\title{
Neonatal Testicular Torsion: Is it Time for Consensus?
}

Ranjit I. Kylat

Department of Pediatrics, College of Medicine,

University of Arizona, AZ, USA
Testicular torsion (TT) occurring in the newborn period has been called neonatal TT (NTT) or perinatal TT. Most of these are asymptomatic, occur prenatally, and are difficult to diagnose. Almost all NTT are extravaginal. There is a lack of consensus in the approach to management of this rare condition. An emergent surgical exploration could salvage, the asymptomatic bilateral TT and prevent asynchronous torsion. After a thorough review of the evidence, the conclusion is that NTT should be managed like TT at any other age group, except that nonoperative maneuvers may not be successful.

KEYWORDS: Intravaginal testicular torsion, neonatal testicular torsion, orchiopexy, perinatal testicular torsion

\section{INTRODUCTION}

Testicular torsion (TT) in the neonatal period 2 is rare and it occurs in 6.1 per 100,000 live births. ${ }^{[1]}$ TT leads to testicular ischemia and later to atrophy and if bilateral can lead to infertility and endocrinological dysfunction. ${ }^{[2]}$ Neonatal TT (NTT) is usually extravaginal, $90 \%$ of these occur in neonates and related to lack of fixation and abnormal mobility of the testicle. ${ }^{[3]}$ NTT occurs during the testicular descent into the scrotum, and many occur in utero. ${ }^{[3]}$ After the neonatal period, torsion occurs inside the tunica vaginalis - intravaginal torsion, the form of torsion seen in $90 \%$ of infants, children and those with undescended testes. $^{[3]}$ We are presenting an unusual occurrence of intravaginal NTT in the $1^{\text {st }}$ day of life, and there are only three reports of this type in this age group. ${ }^{[4]}$

\section{INSTRUCTIVE CASE}

A male infant was born at gestational age of 38 weeks to a 19-year-old primigravida. The mother had regular prenatal care, and her pregnancy course was unremarkable. The infant born through vaginal delivery weighed $3955 \mathrm{~g}$ ( $>98^{\text {th }}$ percentile), and head circumference was $36 \mathrm{~cm}$ ( $>90^{\text {th }}$ percentile). The patient had normal vital signs. Examination revealed a left testicular mass at birth which was hard, elevated, slightly enlarged and not trans-illuminant. Abdominal masses were not detected, and the right testicle was descended and normal. He had normal a complete blood count and

\begin{tabular}{|l|l|}
\hline \multicolumn{2}{|c|}{ Access this article online } \\
\hline Quick Response Code: & Website: \\
\hline & www.jcnonweb.com \\
\hline
\end{tabular}

electrolytes. Scrotal and testicular ultrasound showed thickening surrounding the left testicle possibly due to thickening of the tunica vaginalis with absent blood flow on power Doppler imaging consistent with a TT. The right testicle measured $1.4 \mathrm{~cm} \times 0.9 \mathrm{~cm} \times 1.0 \mathrm{~cm}$ with uniform echotexture without focal abnormality or significant asymmetry. Arterial and venous blood flow was demonstrated by spectral Doppler in the right testicle, along with a moderate right hydrocele. At $18 \mathrm{~h}$ of age, when operated on, an unusual intravaginal torsion, with necrotic left testis which had twisted on its blood supply was seen. The patient underwent left scrotal orchiectomy and right scrotal orchiopexy. Pathology revealed infarction and fibrosis. A follow-up visit, 6 months later, did not show any evidence of testicular atrophy on the right.

\section{DisCUSSION}

A scrotal swelling in the newborn period is easily missed and could be due to birth trauma, breech delivery, epididymo-orchitis, appendicitis, adrenal hemorrhage, idiopathic scrotal hemorrhage, hydrocele, and TT. ${ }^{[3]}$ NTT is also called perinatal TT, with most testes undergoing torsion prenatally, and in about $20 \%$ it occurs after

Address for correspondence: Dr. Ranjit I. Kylat, Department of Pediatrics, Division of Neonatal-Perinatal Medicine and Developmental Biology, College of Medicine, University of Arizona, PO Box 245 073, 1501 N Campbell Avenue, Tucson, AZ 85724, USA.

E-mail: rkylat@gmail.com

This is an open access article distributed under the terms of the Creative Commons Attribution-NonCommercial-ShareAlike 3.0 License, which allows others to remix, tweak, and build upon the work non-commercially, as long as the author is credited and the new creations are licensed under the identical terms.

For reprints contact: reprints@medknow.com

How to cite this article: Kylat RI. Neonatal testicular torsion: Is it time for consensus?. J Clin Neonatol 2017;6:53-6. 
birth. ${ }^{[1,3]}$ NTT is generally asymptomatic, without local tenderness and is difficult to diagnose. Examination findings of NTT generally show a nontranslucent unilateral scrotal swelling with a firm, discolored testicle. Tenderness and absence of cremasteric reflex are unreliable signs in this age group. In some patients, there could be asymptomatic bilateral involvement, at the time of diagnosis (synchronous or metachronous) or later in life (asynchronous). Clinical diagnosis is generally sufficient, but ultrasound using high-frequency linear transducer and color Doppler can be used to exclude a rare differential diagnosis and for the viability of the contralateral testicle, for synchronous bilateral involvement. ${ }^{[5-7]}$

There is considerable controversy and variability in the management. The major differences in opinion are related to timing and value of emergent surgery, risks of anesthesia, inguinal or scrotal approach for surgery, occurrence of bilateral synchronous or asynchronous torsion and method of fixation of the contralateral testicle. The grounds for confusion are many, with some contradictory literature, and we review the evidence to date.

Testicular salvage after surgery is low in infancy and was documented in $6 \%$ of neonates and in infants up to $17 \%{ }^{[3]}$ Even when emergent surgery was done within $3 \mathrm{~h}$ after diagnosis in a case of bilateral NTT, it could not prevent bilateral testicular atrophy. ${ }^{[8]}$ In a further review of bilateral torsion, when scrotal exploration was done, on the same day as diagnosis, the authors found that all infants had bilateral testicular atrophy. ${ }^{[9]}$ They tried to differentiate between urgent surgery done within few hours and early surgery done within days and concluded that the literature does not offer a consensus. ${ }^{[9]}$ Djahangirian et al., argues that there seems to be no advantage to early intervention and that there is no need for orchiectomy, as torsion leads to ipsilateral testicular atrophy and contralateral orchiopexy should be deferred until the risks of anesthesia and surgery are improved. ${ }^{[10]}$ Kaye devised a management algorithm and opined that if the findings of unilateral torsion are present at birth, it is likely prenatal in origin and the chance of salvaging the testis is low. He recommended ipsilateral orchiectomy and contralateral orchiopexy after a month of age, through an inguinal approach. ${ }^{[1]}$

Lopez and Beasley suggested that "even though the risk of bilateral asynchronous torsion is small, the consequences of bilateral anorchia are devastating and given the relative safety of prophylactic orchiopexy, in an increasingly litigious society, performing contralateral fixation earlier (at 3 months) rather than later was preferred, due to the small but definite risk of asynchronous torsion". ${ }^{[12]}$ Callewaert suggested that immediate surgery is mandatory in suspected bilateral torsions and in cases of possible unilateral torsions that there is no place for a more fatalistic "wait-and-see" approach. ${ }^{[13]}$ They even suggested that, if a necrotic testicle is found, it should not be removed during surgery, as some endocrine function may be retained. ${ }^{[13]}$ In another case report of bilateral NTT, the authors suggested that "there was a growing trend of emergency scrotal exploration with contralateral fixation of the testis, as delaying surgery in the postnatal period for prenatally occurring unilateral torsion risks loss of one or both testes, due to a significant risk of bilateral torsion" ${ }^{[14]}$ In a retrospective series in Denmark, it was noted that in $85 \%$ the testis was nonviable at the time of surgery and in only $10 \%$ was it salvageable, even though their conclusion was that "doctor's delay was common for this rare disease". ${ }^{[15]}$ In another literature review, it was suggested that prevention of contralateral TT is paramount and the evidence called for immediate surgical intervention. ${ }^{[16]}$ In a retrospective review of all case series of NTT, the overall salvage rate was $<10 \%$, but when the operation was specified as an emergency, salvage rate seen was $22 \%$ with the authors concluding that early surgery with of the contralateral fixation would be ideal. ${ }^{[17]}$ Roth et al. reported that after they adopted a strategy of emergent surgical exploration in cases of prenatal torsion, anorchia was minimized in patients with bilateral asynchronous torsion. ${ }^{[18]}$

In a survey of Canadian pediatric urologists, Guerra found that only around $67 \%$ would operate for torsion in the neonatal period. ${ }^{[19]}$ Further, in cases of atrophic testis, none of the respondents opted for immediate surgery, with $<40 \%$ suggesting, a delayed contralateral orchiopexy. Among the Canadian urologists, a scrotal incision was preferred by only around $50 \%{ }^{[19]}$ As a commentary to this survey, Salle expressed surprise, that many did not feel that contralateral exploration or fixation was needed and that younger surgeons would operate immediately. ${ }^{[20]}$ In Synder versus Diamond, opposing expert views of observation and emergent surgery were quite eloquently argued, with the merits of each position carefully analyzed. ${ }^{[21]}$ Further, in an editorial comment, it was suggested that, if there are no acute changes in an asymptomatic neonate, a recommendation for surgical exploration is not warranted. ${ }^{[22]}$

A survey of surgeons and urologists working in the British Isles found that, even though $75 \%$ explore the scrotum, only a few surgeons undertake emergent exploration. ${ }^{[5]}$ Twenty-two percent of surgeons reported that they do not perform contralateral orchiopexy, with concerns of damaging a healthy testicle. Amongst those 
who performed it, $50 \%$ used nonabsorbable suture fixation and $31 \%$ by creating a sutureless extradartos pouch. ${ }^{[5]}$ A similar survey amongst pediatric urologists in the USA found that in a neonate with prenatal torsion, only $10 \%$ would not explore or perform a contralateral orchiopexy. In a neonate with postnatal torsion, 98\% would operate urgently, and 96\% would perform a contralateral orchiopexy. ${ }^{[23]}$ The surgical approach preferred was via a scrotal incision. ${ }^{[23]}$ The wide disparity in these three surveys sheds some light to the ongoing controversies in the management. ${ }^{[5,18,23]} \mathrm{In}$ another expert commentary, Friedman suggest that the risks of general anesthesia during the neonatal period should be considered against the potential devastation of anorchia, should contralateral torsion occur. ${ }^{[24]}$

Inguinal exploration to examine for a patent processus vaginalis risks spermatic cord, testicular or vasal injury and the potential for a later development of hydrocele or hernia. Hence most prefer a scrotal approach. ${ }^{[18,23,25]}$ The testicular workup for ischemia and suspected torsion score, which uses urological history and physical examination to assess risk of torsion, has been validated for older children but is not useful in NTT. ${ }^{[26]}$ There is no literature in the newborn of successful nonoperative maneuvers being performed.

Reports of intravaginal TT are extremely rare in the neonatal period and early infancy. ${ }^{[4,27,28]}$ The postulated reasons for this type of $\mathrm{TT}$, are related to excessive laxity of gubernaculum testis and a high attachment of the tunica vaginalis to the spermatic cord. ${ }^{[4]}$ This could also be related to an anatomical defect of the tunica vaginalis, which can be bilateral. Hence the fixation of the contralateral testis is important to prevent any future torsion. ${ }^{[4]}$

The patient described was asymptomatic, and an early physical examination revealed the subtle differences in size and color of the scrotum and testes. The timely intervention did not salvage the affected testicle but likely prevented an asynchronous torsion on the unaffected side. This rare condition reinforces the need for careful physical examination of every newborn infant soon after delivery and for emergent evaluation and surgery for suspected NTT. A further reason for that is that synchronous bilateral TT could be missed on physical examination and only identified on surgical exploration of unilateral NTT. Emergent surgery may result in salvage of the contralateral torted testis. ${ }^{[18,23,24]}$ Our plea would be that the obviously atrophic testicle is difficult to detect in the immediate newborn period. Neonatal, perinatal and prenatal TT are terms being used, but there is no reason, that emergent treatment, as offered to older infants and children should be withheld in this population. Currently, neonatal anesthesia is available in all accredited hospitals and the risks of anesthesia are extremely low in neonates with the availability of pediatric anesthesiologists. The consideration of litigation and parental anxiety are all factors some would take in the overall management plan of a patient. However, the paramount treatment plan would be evidence-based care, which now points toward immediate surgery through a scrotal approach with a view to salvaging the affected side, if possible and contralateral fixation. Non-operative maneuvers to reduce NTT are never successful. This is the best way to prevent later anorchia, infertility, and hormonal issues. The questions which are still left to be answered are the method of fixation without sutures or through a dartos pouch.

\section{Financial support and sponsorship}

Nil.

\section{Conflicts of interest}

There are no conflicts of interest.

\section{REFERENCES}

1. Abraham MB, Charles A, Gera P, Srinivasjois R. Surgically managed perinatal testicular torsion: A single centre experience. J Matern Fetal Neonatal Med 2016;29:1265-8.

2. Riaz-Ul-Haq M, Mahdi DE, Elhassan EU. Neonatal testicular torsion; A review article. Iran J Pediatr 2012;22:281-9.

3. Mano R, Livne PM, Nevo A, Sivan B, Ben-Meir D. Testicular torsion in the first year of life - Characteristics and treatment outcome. Urology 2013;82:1132-7.

4. Bordin G, Parolini F, Morandi A, Farris G, Leva E, Torricelli M. Intravaginal testicular torsion in newborns. To fix or not to fix the contralateral testis? Pediatr Med Chir 2013;35:225-7.

5. Rhodes HL, Corbett HJ, Horwood JF, Losty PD. Neonatal testicular torsion: A survey of current practice amongst paediatric surgeons and urologists in the United Kingdom and Ireland. J Pediatr Surg 2011;46:2157-60.

6. Xiao H, Gao Y, Li Y, Tang Y, Zhu L, Xu J, et al. Ultrasound assessment of perinatal testicular torsion. Br J Radiol 2016; 89 (1064): [Epub ahead of print].

7. Riccabona M, Darge K, Lobo ML, Ording-Muller LS, Augdal TA, Avni FE, et al. ESPR uroradiology taskforce - Imaging recommendations in paediatric uroradiology, Part VIII: Retrograde urethrography, imaging disorder of sexual development and imaging childhood testicular torsion. Pediatr Radiol 2015;45:2023-8.

8. Bagci S, Bachour H, Woelfle JF, Mueller A, Bartmann P, Franz AR. Bilateral perinatal testicular torsion in an infant: A rare neonatal emergency. Pediatr Int 2010;52:e227-8.

9. Samnakay N, Tudehope D, Walker R. Spin on perinatal testicular torsion. J Paediatr Child Health 2006;42:734-6.

10. Djahangirian $\mathrm{O}$, Ouimet A, Saint-Vil D. Timing and surgical management of neonatal testicular torsions. J Pediatr Surg 2010;45:1012-5.

11. Kaye JD, Levitt SB, Friedman SC, Franco I, Gitlin J, Palmer LS. Neonatal torsion: A 14-year experience and proposed algorithm for management. J Urol 2008;179:2377-83.

12. Lopez RN, Beasley SW. Testicular torsion: Potential pitfalls 
in its diagnosis and management. J Paediatr Child Health 2012;48:E30-2.

13. Callewaert PR, Van Kerrebroeck P. New insights into perinatal testicular torsion. Eur J Pediatr 2010;169:705-12.

14. Granger J, Brownlee EM, Cundy TP, Goh DW. Bilateral perinatal testicular torsion: Successful salvage supports emergency surgery. BMJ Case Rep 2016;2016. pii: Bcr2016216020.

15. Jensen R, Ellebæk M, Rasmussen L, Qvist N. Low success rate of salvage surgery for testicular torsion in newborns. Dan Med J 2015;62:A4997.

16. Massoni F, Troili GM, Pelosi M, Ricci S. Perinatal testicular torsion and medicolegal considerations. Minerva Pediatr 2014;66:229-32.

17. Nandi B, Murphy FL. Neonatal testicular torsion: A systematic literature review. Pediatr Surg Int 2011;27:1037-40.

18. Roth CC, Mingin GC, Ortenberg J. Salvage of bilateral asynchronous perinatal testicular torsion. J Urol 2011;185 6 Suppl: 2464-8.

19. Guerra LA, Wiesenthal J, Pike J, Leonard MP. Management of neonatal testicular torsion: Which way to turn? Can Urol Assoc J 2008;2:376-9.

20. Salle JL. Perinatal testicular torsion. Can Urol Assoc J 2008;2:380.

21. Snyder HM, Diamond DA. In utero/neonatal torsion: Observation versus prompt exploration. J Urol 2010;183:1675-7.

22. Snyder HM $3^{\text {rd }}$. Editorial comment. J Urol 2011;185 6 Suppl: 2468.

23. Broderick KM, Martin BG, Herndon CD, Joseph DB, Kitchens DM. The current state of surgical practice for neonatal torsion: A survey of pediatric urologists. J Pediatr Urol 2013;9:542-5

24. Friedman AA, Elder JS. Words of wisdom: Re: The current state of surgical practice for neonatal torsion: A survey of pediatric urologists. Eur Urol 2013;64:513-5.

25. Kaefer M, Agarwal D, Misseri R, Whittam B, Hubert K, Szymanski K, et al. Treatment of contralateral hydrocele in neonatal testicular torsion: Is less more? J Pediatr Urol 2016;12:306.e1-4.

26. Sheth KR, Keays M, Grimsby GM, Granberg CF, Menon VS, DaJusta DG, et al. Diagnosing testicular torsion before urological consultation and imaging: Validation of the TWIST score. J Urol 2016;195:1870-6.

27. Fernández MS, Domínguez $\mathrm{C}$, López A, Benlloch $\mathrm{C}$, García-Ibarra F. Neonatal intravaginal testicular torsion in an undescended testis. Cir Pediatr 1996;9:128-9.

28. Tucci S Jr., Beduschi MC. Intravaginal perinatal torsion of the spermatic cord. J Pediatr (Rio J) 1996;72:419-21.

\section{"Quick Response Code" link for full text articles}

The journal issue has a unique new feature for reaching to the journal's website without typing a single letter. Each article on its first page has a "Quick Response Code". Using any mobile or other hand-held device with camera and GPRS/other internet source, one can reach to the full text of that particular article on the journal's website. Start a QR-code reading software (see list of free applications from http://tinyurl.com/ yzlh2tc) and point the camera to the QR-code printed in the journal. It will automatically take you to the HTML full text of that article. One can also use a desktop or laptop with web camera for similar functionality. See http://tinyurl.com/2bw7fn3 or http://tinyurl.com/3ysr3me for the free applications. 